\title{
Influence of Light of Different Spectral Compositions on the Growth, Photosynthesis, and Expression of Light-Dependent Genes of Scots Pine Seedlings
}

\author{
Pavel Pashkovskiy ${ }^{1, *}$, Vladimir D. Kreslavski ${ }^{2}$, Yury Ivanov ${ }^{1}$, Alexandra Ivanova ${ }^{1}$, Alexander Kartashov ${ }^{1}{ }^{10}$, \\ Alexander Shmarev ${ }^{2} \mathbb{D}$, Valeriya Strokina ${ }^{2}$, Vladimir V. Kuznetsov ${ }^{1}$ and Suleyman I. Allakhverdiev ${ }^{1, *(1)}$ \\ 1 K.A. Timiryazev Institute of Plant Physiology, Russian Academy of Sciences, Botanicheskaya Street 35, \\ 127276 Moscow, Russia; ivanovinfo@mail.ru (Y.I.); aicheremisina@mail.ru (A.I.); botanius@yandex.ru (A.K.); \\ vlkuzn@mail.ru (V.V.K.) \\ 2 Institute of Basic Biological Problems, Russian Academy of Sciences, Institutskaya Street 2, \\ 142290 Pushchino, Russia; vkreslav@rambler.ru (V.D.K.); shurik_bx_04@mail.ru (A.S.); strokina.93@mail.ru (V.S.) \\ * Correspondence: pashkovskiy.pavel@gmail.com (P.P.); suleyman.allakhverdiev@gmail.com (S.I.A.)
}

\section{check for} updates

Citation: Pashkovskiy, P.; Kreslavski, V.D.; Ivanov, Y.; Ivanova, A.;

Kartashov, A.; Shmarev, A.; Strokina,

V.; Kuznetsov, V.V.; Allakhverdiev, S.I.

Influence of Light of Different

Spectral Compositions on the Growth, Photosynthesis, and Expression of Light-Dependent Genes of Scots Pine Seedlings. Cells 2021, 10, 3284.

https://doi.org/10.3390/cells10123284

Academic Editor: Seiji Akimoto

Received: 22 October 2021

Accepted: 22 November 2021

Published: 24 November 2021

Publisher's Note: MDPI stays neutral with regard to jurisdictional claims in published maps and institutional affiliations.

Copyright: (C) 2021 by the authors. Licensee MDPI, Basel, Switzerland. This article is an open access article distributed under the terms and conditions of the Creative Commons Attribution (CC BY) license (https:/ / creativecommons.org/licenses/by/ $4.0 /)$.
Abstract: Varying the spectral composition of light is one of the ways to accelerate the growth of conifers under artificial conditions for the development of technologies and to obtain sustainable seedlings required to preserve the existing areas of forests. We studied the influence of light of different quality on the growth, gas exchange, fluorescence indices of $\mathrm{Chl} a$, and expression of key light-dependent genes of Pinus sylvestris L. seedlings. It was shown that in plants growing under red light (RL), the biomass of needles and root system increased by more than two and three times, respectively, compared with those of the white fluorescent light (WFL) control. At the same time, the rates of photosynthesis and respiration in RL and blue light (BL) plants were lower than those of blue red light (BRL) plants, and the difference between the rates of photosynthesis and respiration, which characterizes the carbon balance, was maximum under RL. RL influenced the number of xylem cells, activated the expression of genes involved in the transduction of cytokinin (Histidinecontaining phosphotransfer 1, HPT1, Type-A Response Regulators, $R R-A$ ) and auxin (Auxin-induced protein 1, $A u x / I A A)$ signals, and reduced the expression of the gene encoding the transcription factor phytochrome-interacting factor 3 (PIF3). It was suggested that RL-induced activation of key genes of cytokinin and auxin signaling might indicate a phytochrome-dependent change in cytokinins and auxins activity.

Keywords: photomorphogenesis; Pinus sylvestris; light of various spectral composition; photosynthesis; chlorophyll fluorescence; gene expression; pigment content

\section{Introduction}

The quality of light is an important factor in regulating plant growth and development during ontogenesis, including germination, photomorphogenesis, flowering induction, etc. At the beginning of ontogenesis, most plants are forced to vegetate under shading conditions while growing underneath taller plants, which also leads to a decrease in the quality of light. Green and far-red light (FRL) predominate under the forest canopy because light in the red and blue ranges of the spectrum is effectively absorbed by the chlorophyll of taller plants. This forces the seedlings of most woody plants to adapt to indifferent light qualities [1]. For example, plants growing under a forest canopy acclimatize to a low red:far red (R:FR) ratio, which causes shoot elongation [1]. It was previously shown that blue light (BL), on the contrary, inhibits shoot growth $[2,3]$. This leads to plants with a high BL level and a high R:FR ratio growing low but with an increased leaf surface, which in turn affects the intensity of photosynthesis [4].

The observed changes in the global climate under all forecast scenarios suggest a decline in coniferous species in the temperate zone of Europe [5]. In this regard, the 
development of technologies for obtaining sustainable seedlings is required to preserve the existing areas of coniferous forests. Varying the spectral composition of light can be one of the simplest ways to accelerate the growth of seedlings under artificial conditions [6]. However, to select the optimal spectral composition of light under artificial light conditions, it is necessary to know how the light of different spectral ranges affects the growth and photosynthetic parameters of seedlings of coniferous plants.

Plants have several types of photoreceptors that respond to changes in environmental light conditions. Under natural light, plants are simultaneously exposed to light of different wavelengths, resulting in cross-signaling of light between multiple photoreceptors. Phytochromes are among the most characterized photoreceptors. They are RL and FRL sensors and they regulate many developmental processes, including seed germination and hypocotyl growth [1]. Other well-known receptors, the cryptochromes, perceive light in the blue and UV ranges of the spectrum. They are involved in the growth processes and de-etiolation of seedlings and are also involved in circadian rhythms [7]. Photoreceptors have been studied in detail in Arabidopsis thaliana. They include five phytochromes (PHYA to PHYE) and two major cryptochromes (CRY1 and CRY2). In gymnosperms, PHYN is orthologous to PHYA of angiosperms, while PHYO is orthologous to PHYC [8]. In addition, gymnosperms have PHYP, which genetically occupies an intermediate position between the PHYB of Oryza sativa and the PHYE of Arabidopsis thaliana [9]. From the experiments carried out by Clapham et al., 2002, it was found that pine and spruce react to the RL/FRL ratio differently than angiosperms, which confirms the uniqueness of the phytochrome system of gymnosperms [10].

In addition to the quality of light, plant growth is also affected by hormonal balance [11]. The lighting conditions cause the level of hormones in plants to change, which leads to a change in photosensitivity. For example, exogenous hormones can stimulate plant growth by acting as mediators in the processes of light signal transduction [12]. In turn, light by photoreceptors regulates the metabolism of various hormonal signals. Thus, PHYA affects the metabolic pathways of gibberellins and indoleacetic acid [11], as well as key components of light signaling, such as the transcriptional factors (TFs): PIF3, PIF4, and HY5 [13]. The main phytohormones are associated with light-mediated growth regulation [14-16], while the stimulation of cell growth involves auxins and cytokinins [17-19]. The light of different spectral compositions affects the activity of endogenous hormones through the regulation of secondary metabolism; for example, blue light promotes the accumulation of flavonoids, which in turn affects the polar transport of auxin [20].

The aim of this work was to understand how the conditions of light of different spectral composition affect the growth, morphometric, and photosynthetic characteristics of Pinus sylvestris seedlings. At the same time, special attention was given to the possible relationships of the processes of growth, photosynthesis, and respiration with the intensity of expression of the main genes encoding proteins of photosystems, and the genes involved in light and hormonal signalling of Pinus sylvestris plants under light of various spectral quality. The obtained results can be used to create artificial lighting systems in forest nurseries to accelerate the cultivation of planting material, and they also have applications in biotechnology.

\section{Materials and Methods}

\subsection{Plant Materials and Experimental Design}

Seeds of Scots pine (P. sylvestris L.) were collected in the Bryansk region (Bryansk, Russia) from high-productivity pine stands in complex forest types. Seeds were germinated and grown in hydroculture on individual substrates in polypropylene cartridges filled with $1 \%$ agar bungs in individual boxes of the climatic chamber under red (maxima of $660 \mathrm{~nm}$ ), blue (maxima of $450 \mathrm{~nm}$ ), red + blue (maxima of 660 and $450 \mathrm{~nm}$ ) LEDs, as well as under fluorescent lamps (58 W/33-640, white fluorescent lamps (Philips, Pila, Poland), $130 \pm 10 \mu \mathrm{mol}$ (photons) $\mathrm{m}^{-2} \mathrm{~s}^{-1}$ ) for 6 weeks. (Figure 1). 


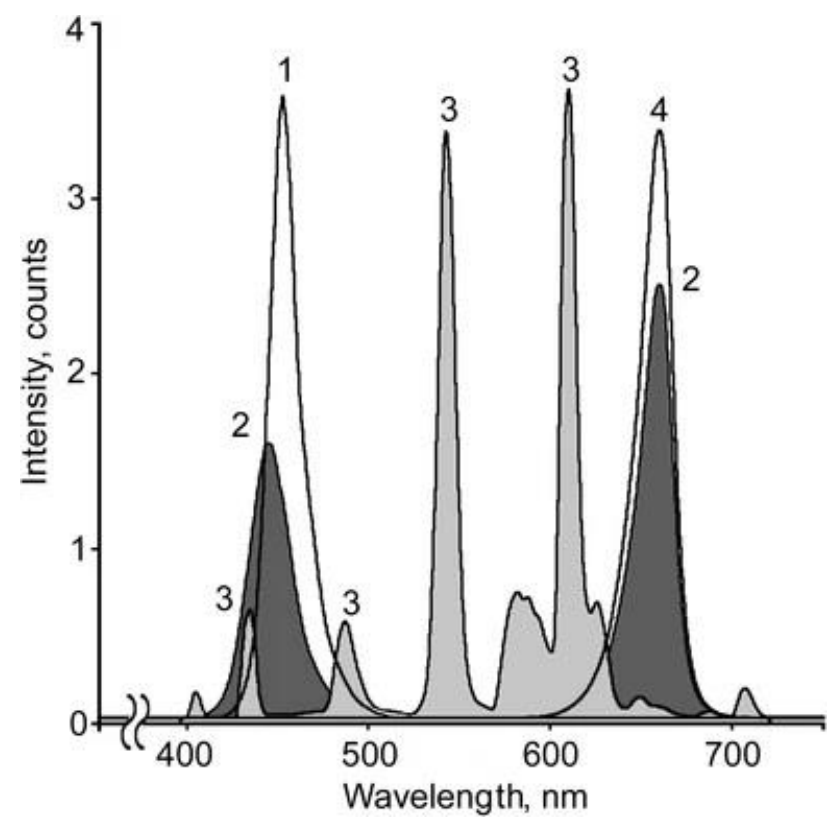

Figure 1. Emission spectra of the light sources used in the experiments. Spectra of blue light (BL) with a peak at $450 \mathrm{~nm}$ (1), blue + red (BRL) with two maxima at $445 \mathrm{~nm}$ and $660 \mathrm{~nm}$ (2), white fluorescent lamps (WFL) with a set of peaks in the visible spectral region (3), and red light (RL) with a peak at $660 \mathrm{~nm}(4)$.

After seed coat rupture and cotyledon expansion, the seedlings were transferred to a nutrient solution [21]. The seedlings were cultivated in $6 \mathrm{~L}$ plastic trays $(171$ seed beds per tray) in a growth chamber that provided a constant air temperature of $24 \pm 2{ }^{\circ} \mathrm{C}$ and a $16 \mathrm{~h}$ photoperiod. The nutrient solutions were constantly aerated and renewed once a week. During the week, a constant volume of the nutrient solution was maintained by adding distilled water.

The fresh biomass of the roots and needles was determined using an analytical balance (Scout Pro SPU123, Ohaus Corporation, Parsippany, NJ, USA) with an accuracy of $1 \mathrm{mg}$, after which the samples were fixed in liquid nitrogen and stored at $-70^{\circ} \mathrm{C}$ until biochemical analyses. The fixation was carried out under the conditions of the light in which the plants grew without exposure to another light.

\subsection{Pigment Contents}

The contents of chlorophyll $a(\mathrm{Chl} a)$ and $b(\mathrm{Chl} b)$ and total carotenoids (Car) in pigment extracts of all studied needles were determined spectrophotometrically in $80 \%$ acetone [22].

\subsection{Measurements of $\mathrm{CO}_{2}$ Gas Exchange}

The photosynthetic rate $\left(\mathrm{P}_{\mathrm{n}}\right)$ was determined in a closed system under light conditions using an LCPro + portable infrared gas analyser from ADC BioScientific Ltd. (United Kingdom) connected to a leaf chamber. The $\mathrm{CO}_{2}$ uptake per leaf area $\left(\mu \mathrm{mol} \mathrm{m}{ }^{-2} \mathrm{~s}^{-1}\right)$ was determined. The rate of photosynthesis of the leaves in the second layer from the top was determined at a saturating light intensity of $1000 \mu \mathrm{mol}$ (photons) $\mathrm{m}^{-2} \mathrm{~s}^{-1}$. Previously, we recorded the light curves in the interval of intensities from 0 to $1200 \mu \mathrm{mol}$ (photons) $\mathrm{m}^{-2} \mathrm{~s}^{-1}$. The light intensities in the region from 600 to $1200 \mu \mathrm{mol}$ (photons) $\mathrm{m}^{-2} \mathrm{~s}^{-1}$ were saturated. After measuring the rate of photosynthesis, the light was turned off, and the rate of dark respiration was measured. 


\subsection{Determination of Photochemical Activity}

Fluorescence parameters characterizing the state of the photosynthetic apparatus were calculated on the basis of induction fluorescence curves obtained using data from the JIP test, which is usually used to evaluate the state of PSII. Chlorophyll (Chl) fluorescence induction curves (OJIP curves) were recorded with the setup Plant Efficiency Analyser (Handy-PEA, Hansatech Instruments Ltd., London, UK). For the JIP test, OJIP curves were measured under illumination with blue light at an intensity of $3500 \mu \mathrm{mol}$ (photons) $\mathrm{m}^{-2} \mathrm{~s}^{-1}$ for $1 \mathrm{~s}$.

On the basis of induction fluorescence curves (OJIP curves), the following parameters, which characterize the PSII photochemical activity, were calculated: $F_{v} / F_{m}$, the PSII maximum quantum photochemical yield, and $\mathrm{PI}_{\mathrm{ABS}}$, the PSII performance index $[23,24]$. Here, $F_{v}$ is the value of variable fluorescence, equal to the difference between $F_{m}$ and $F_{0}$; $\mathrm{F}_{0}$ is the minimum amplitude of fluorescence $(\mathrm{F})$, and $\mathrm{F}_{\mathrm{m}}$ is the maximum amplitude of fluorescence. For calculation of the $\mathrm{PI}_{\mathrm{ABS}}$, the following formula was used:

$$
\left.\mathrm{PI}_{\mathrm{ABS}}=\left(\mathrm{F}_{\mathrm{v}} / \mathrm{F}_{\mathrm{m}}\right) /\left(\mathrm{M}_{0} / \mathrm{V}_{\mathrm{j}}\right) \times\left(\mathrm{F}_{\mathrm{v}} / \mathrm{F}_{0}\right) \times\left(1-\mathrm{V}_{\mathrm{j}}\right) / \mathrm{V}_{\mathrm{j}}\right) ; \mathrm{M}_{0}=4 \times\left(\mathrm{F}_{300 \mu \mathrm{s}}-\mathrm{F}_{0}\right) /\left(\mathrm{F}_{\mathrm{m}}-\mathrm{F}_{0}\right) ; \text { and } \mathrm{V}_{\mathrm{j}}=\left(\mathrm{F}_{2 \mathrm{~ms}}-\mathrm{F}_{0}\right) /\left(\mathrm{F}_{\mathrm{m}}-\mathrm{F}_{0}\right)
$$

where $\mathrm{M}_{0}$ is the average value of the initial slope of the relative variable fluorescence of $\mathrm{Chl} a$, which reflects the closing rate of the PSII reaction centers, and $\mathrm{V}_{\mathrm{j}}$ is the relative level of fluorescence in phase J after $2 \mathrm{~ms}$.

PAM fluorimetry (Junior-PAM, Walz, Germany) was used to evaluate the photosynthetic apparatus state. The values $\mathrm{F}_{0}, \mathrm{~F}_{\mathrm{v}}, \mathrm{F}_{\mathrm{m}}, \mathrm{F}_{\mathrm{m}}{ }^{\prime}$, and $\mathrm{F}^{\prime}$, as well as the PSII maximum $\left(F_{v} / F_{m}\right)$ and effective $Y($ II $)\left(F_{m}{ }^{\prime}-F_{t}\right) / F_{m}{ }^{\prime}$ photochemical quantum yields and nonphotochemical quenching (NPQ) $\left(\mathrm{F}_{\mathrm{m}} / \mathrm{F}_{\mathrm{m}}{ }^{\prime}-1\right)$, were determined. Here, $\mathrm{F}_{\mathrm{m}}$ and $\mathrm{F}_{\mathrm{m}}{ }^{\prime}$ are the maximum $\mathrm{Chl}$ fluorescence levels under dark- and light-adapted conditions, respectively. $F_{v}$ is the photoinduced change in fluorescence, and $F_{t}$ is the level of fluorescence before a saturation impulse is applied. $\mathrm{F}_{0}$ is the initial Chl fluorescence level. Actinic light was switched on for $10 \mathrm{~min}\left[\mathrm{I}=125 \mu \mathrm{mol}\right.$ (photons) $\left.\mathrm{m}^{-2} \mathrm{~s}^{-1}\right]$.

\subsection{RNA Extraction and $q R T-P C R$}

RNA isolation was performed according to the method of Kolosova et al. (2004) [25] with some modifications suggested by Pashkovskiy et al. (2019) [26]. The quantity and quality of the total RNA were determined using a NanoDrop 2000 spectrophotometer (Thermo Fisher Scientific, Waltham, MA, USA). cDNA synthesis was performed using the M-MLV Reverse Transcriptase Kit (Fermentas, Canada) and the oligo (dT) 21 primer for genes of nuclear coding and random 6 (Evrogen, Moscow, Russia) for chloroplast coding genes expression. The expression patterns of the genes were assessed using the CFX96 Touch $^{\mathrm{TM}}$ Real-Time PCR Detection System (Bio-Rad, Hercules, CA, USA). The transcript levels were normalized to the expression of the Actin 1 gene. The mRNA levels were expressed as a ratio of the corresponding values for the WFL plants. The relative gene-expression signal intensity at the WFL plants was considered to have a value of 1 . Gene-specific primers (Table 1) for photosystem II protein D1 (psbA, ABO77179.1), cryptochrome 1 (Cry1, K7R334), cryptochrome 2 (Cry2, T2FFB6), phytochrome P (phyP, AIY54822.1), phytochrome $\mathrm{N}$ (phyN, AFV79519.1), phytochrome O (phyO, A7Y6Q6), phytochrome-interacting factor 3 (PIF3, D5ABG4), chalcone synthase (CHS, AF543757.1), stilbene synthase (STS, S50350.1), histidine-containing phosphotransfer 1 (HPT1, ALN42232.1), type-A response regulators ( $R R-A$, FJ717710.1), and auxin-induced protein 1 (Aux/IAA, AY289600.1) were selected using nucleotide sequences from the National Center for Biotechnology Information (NCBI) database (Available online: http://www.ncbi.nlm.nih.gov (accessed on 15 May 2021)) and database www.uniprot.org (Available online: http:/ / www.uniprot.org (accessed on 20 May 2021)) with Vector NTI Suite 9 software (Invitrogen, Carlsbad, CA, USA). 
Table 1. The primers for qRT-PCR analysis.

\begin{tabular}{|c|c|c|c|c|c|c|}
\hline & \multirow[b]{2}{*}{ Gene Bank ID } & \multirow[b]{2}{*}{ Gene Description } & \multirow[b]{2}{*}{ Plant } & \multirow[b]{2}{*}{ Gene } & \multicolumn{2}{|c|}{ Primer $5^{\prime}-3^{\prime}$} \\
\hline & & & & & Forward & Reverse \\
\hline 1 & $\begin{array}{l}\text { ALN42232.1 } \\
\text { (uniprot.org) }\end{array}$ & $\begin{array}{l}\text { Histidine-containing } \\
\text { phosphotransfer } 1\end{array}$ & Pinus pinaster & HPT1 & $\begin{array}{l}\text { GCTCAAGTAT- } \\
\text { AGGAGCGCGG }\end{array}$ & $\begin{array}{l}\text { CCAGCTTGTTT- } \\
\text { TTCACGAGGT }\end{array}$ \\
\hline 2 & $\begin{array}{c}\text { FJ717710.1 } \\
\text { (ncbi.nlm.nih.gov) }\end{array}$ & $\begin{array}{l}\text { Type-A Response } \\
\text { Regulators }\end{array}$ & Pinus pinea & $R R-A$ & $\begin{array}{l}\text { CAGAAGGCGC- } \\
\text { TCAAGAGTTT }\end{array}$ & $\begin{array}{l}\text { TTGTTGGTCCC- } \\
\text { TGGATCTTC }\end{array}$ \\
\hline 3 & $\begin{array}{c}\text { AY289600.1 } \\
\text { (ncbi.nlm.nih.gov) }\end{array}$ & $\begin{array}{l}\text { Auxin-induced } \\
\text { protein } 1 \text { (IAA1) }\end{array}$ & Pinus taeda & $A u x / I A A$ & $\begin{array}{l}\text { GCCACCTGTC- } \\
\text { AAAGATTTCAG }\end{array}$ & $\begin{array}{c}\text { TGAGGTCCACC- } \\
\text { TTTCTGAGA }\end{array}$ \\
\hline 4 & $\begin{array}{l}\text { ABO77179.1 } \\
\text { (uniprot.org) }\end{array}$ & $\begin{array}{c}\text { Photosystem II } \\
\text { protein D1 }\end{array}$ & $\begin{array}{c}\text { Pinus } \\
\text { sylvestris }\end{array}$ & $p s b A$ & $\begin{array}{l}\text { TGAAGGTTAC- } \\
\text { AGATTCGGTCA }\end{array}$ & $\begin{array}{l}\text { TGAATATGCAA- } \\
\text { CAGCAATCCA }\end{array}$ \\
\hline 5 & $\begin{array}{c}\text { K7R334 } \\
\text { (uniprot.org) }\end{array}$ & Cryptochrome 1 & $\begin{array}{c}\text { Pinus } \\
\text { sylvestris }\end{array}$ & Cry1 & $\begin{array}{l}\text { TATGGTGCACA- } \\
\text { GGGCAGATG }\end{array}$ & $\begin{array}{l}\text { AAGCTGCAGAA- } \\
\text { GCTGTTCCT }\end{array}$ \\
\hline 6 & $\begin{array}{c}\text { T2FFB6 } \\
\text { (uniprot.org) }\end{array}$ & Cryptochrome 2 & Picea abies & Cry2 & $\begin{array}{l}\text { TTCCCTGGCT- } \\
\text { GCAACAGAAA }\end{array}$ & $\begin{array}{l}\text { CCCAACATTGC- } \\
\text { TAGGCAGGA }\end{array}$ \\
\hline 7 & $\begin{array}{c}\text { AIY54822.1 } \\
\text { (uniprot.org) }\end{array}$ & Phytochrome P & $\begin{array}{c}\text { Pinus } \\
\text { sylvestris }\end{array}$ & phyP & $\begin{array}{l}\text { GGCATGTCCC- } \\
\text { TTGTTCAGGA }\end{array}$ & $\begin{array}{l}\text { CTTCTGTGGGCC- } \\
\text { AAAGGTCT }\end{array}$ \\
\hline 8 & $\begin{array}{l}\text { AFV79519.1 } \\
\text { (uniprot.org) }\end{array}$ & Phytochrome N & $\begin{array}{c}\text { Pinus } \\
\text { sylvestris }\end{array}$ & phyN & $\begin{array}{l}\text { GGCTCAGAGG- } \\
\text { AGGACAAAGG }\end{array}$ & $\begin{array}{c}\text { TTCTGCCCGGTC- } \\
\text { ACATCTTG }\end{array}$ \\
\hline 9 & $\begin{array}{c}\text { A7Y6Q6 } \\
\text { (uniprot.org) }\end{array}$ & Phytochrome O & $\begin{array}{c}\text { Pinus } \\
\text { sylvestris }\end{array}$ & phyO & $\begin{array}{l}\text { AGATGTGACG- } \\
\text { TGGCAAAGGA }\end{array}$ & $\begin{array}{l}\text { TGCGGGATTCC- } \\
\text { ACTCAGAAC }\end{array}$ \\
\hline 10 & $\begin{array}{c}\text { D5ABG4 } \\
\text { (uniprot.org) }\end{array}$ & $\begin{array}{l}\text { Phytochrome- } \\
\text { interacting } \\
\text { factor } 3\end{array}$ & Picea sitchensis & PIF3 & $\begin{array}{l}\text { ATCAGCACTT- } \\
\text { CCTGGTTCCG }\end{array}$ & $\begin{array}{l}\text { CAGGCTGAGTT- } \\
\text { GTTCCAGGT }\end{array}$ \\
\hline 11 & $\begin{array}{c}\text { AF543757.1 } \\
\text { (ncbi.nlm.nih.gov) }\end{array}$ & Chalcone synthase & $\begin{array}{l}\text { Pinus } \\
\text { uliginosa }\end{array}$ & CHS & $\begin{array}{c}\text { ATGGCTGCAG- } \\
\text { GAATGATGAAGG }\end{array}$ & $\begin{array}{l}\text { AGTGCCAATAG- } \\
\text { CGAGGATG }\end{array}$ \\
\hline 12 & $\begin{array}{c}\text { S50350.1 } \\
\text { (ncbi.nlm.nih.gov) }\end{array}$ & Stilbene synthase & $\begin{array}{c}\text { Pinus } \\
\text { sylvestris }\end{array}$ & STS & $\begin{array}{l}\text { TCCGACTGGA- } \\
\text { ACAAGTTGTTC }\end{array}$ & $\begin{array}{l}\text { GCTTGGCCTCC- } \\
\text { ACCCGATCAAG }\end{array}$ \\
\hline 13 & $\begin{array}{c}\text { CBB44933.1 } \\
\text { (uniprot.org) }\end{array}$ & Actin 1 & $\begin{array}{l}\text { Pinus } \\
\text { sylvestris }\end{array}$ & Act1 & $\begin{array}{l}\text { TTAGCAACTGG- } \\
\text { GATGACATGGA }\end{array}$ & $\begin{array}{l}\text { CCTGAATGGCA- } \\
\text { ACATACATAGCA }\end{array}$ \\
\hline
\end{tabular}

\subsection{Histochemical Studies of the Hypocotyls}

Anatomical studies were performed using light microscopy methods on live preparations of cross-sections of hypocotyls of $P$. sylvestris seedlings prepared immediately before the study. Sections 10-30 $\mu \mathrm{m}$ thick were prepared using an HM650 V vibrating blade microtome (Thermo Fisher Scientific, Waltham, MA, USA) through the central part of the organ. The obtained sections were stained with 3\% phloroglucinol $/ \mathrm{HCl}$ reagent (Sigma, P3502) for $2 \mathrm{~min}$ and then washed with phosphate buffered saline $(70 \mathrm{mM}, \mathrm{pH}=7.4)$ [27]. The sections were photographed under an Imager D1 light microscope (Carl Zeiss, Oberkochen, Germany) using a Levenhuk M800 PLUS digital photo attachment with a resolution of 8.0 MPI (Levenhuk, Tampa, FL, USA). The resulting images were processed with the public domain software ImageJ v.1.49 (NIH; http://rsb.info.nih.gov/ij). The diameter of the hypocotyl, the number of lignified xylem cells, the sectional area of the hypocotyl, the area of the xylem, and the average sectional area of one xylem cell were determined on the sections of the hypocotyls.

\subsection{Statistics}

The number of biological replicates for the determination of the fresh biomass of the roots and needles ranged from 27 to 39; 13 biological replicates were performed for the histochemical studies of the hypocotyls, and 6 biological replicates were used for photosynthetic and respiration rates as well as photochemical activity. Each plant sample 
fixed in liquid nitrogen was treated as a biological replicate; therefore, there were six biological replicates for the pigment contents and gene expression analyses.

The data were statistically analyzed using SigmaPlot 12.3 (Systat Software, San Jose, USA) with one-way analysis of variance (ANOVA) followed by Duncan's method for normally distributed data (in the figures, significant differences are denoted by different capital letters). Kruskal-Wallis one-way ANOVA was performed on ranks followed by a Student-Newman-Keuls post hoc test or by a Dunn's post hoc test for non-normally distributed data and data with unequal variance (in the figures, significant differences are denoted by different italic letters for the Student-Newman-Keuls post hoc test or by different boldface italic type for the Dunn's post hoc test). Different letters were used to indicate significance at $p<0.05$. The values presented in the tables and figures are the arithmetic means \pm standard errors.

\section{Results}

\subsection{Growth and Morphological Parameters}

Narrowband light caused marked changes in plant morphology and growth (Figure 2).
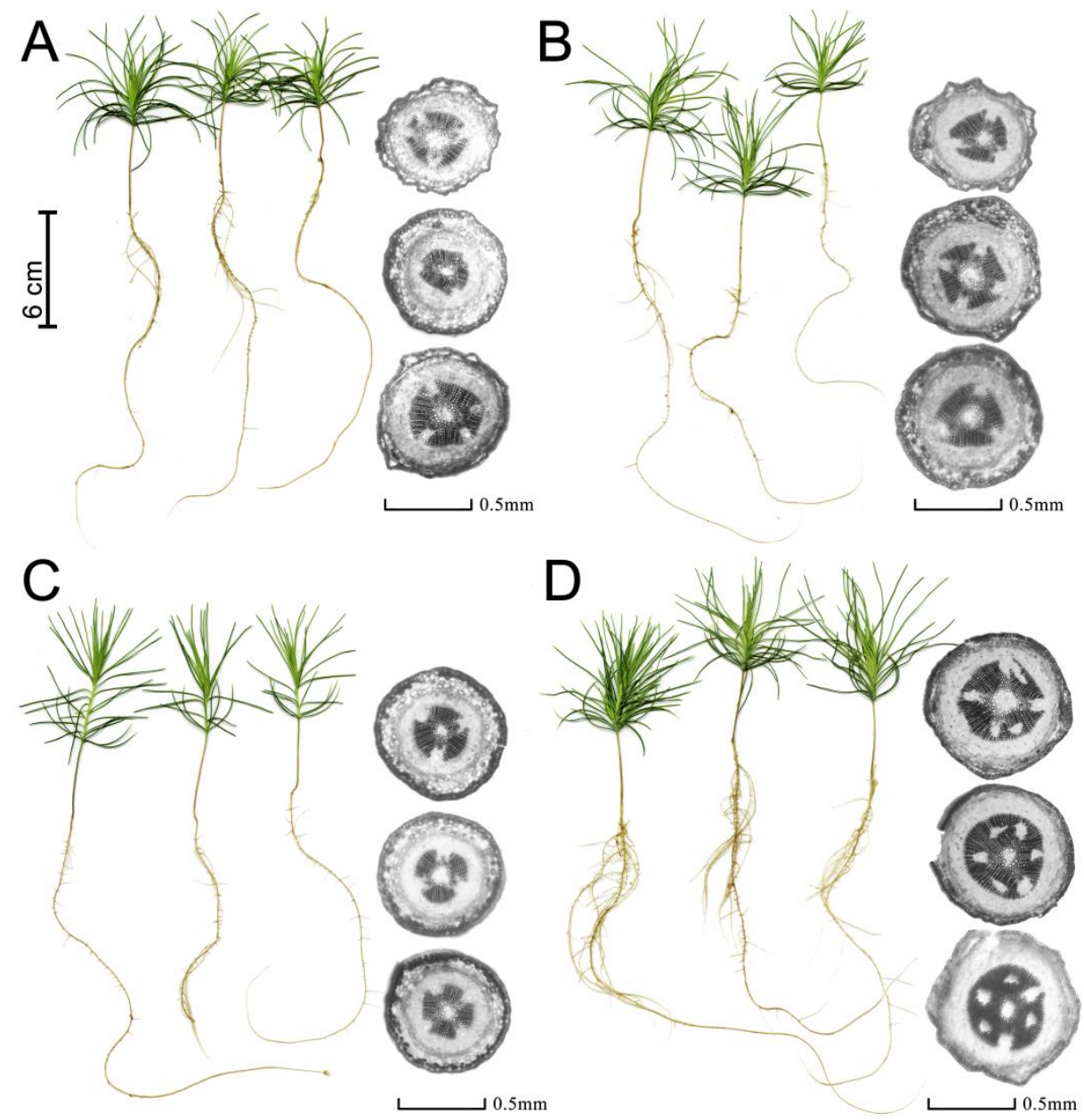

Figure 2. The morphological changes of P. sylvestris seedlings with dependence on light quality. WFL (A), BRL (B), BL (C), and RL (D).

Thus, RL increased the weight of the needles by 2.6 times, and BL increased the weight of the needles by 2.1 times relative to the WFL taken as a control (Figure 3A). BL caused hypocotyl elongation, and plants with RL formed short, larger plants. In addition, plant root weights in the RL variant were 3.8 times higher than the root weight in the control (WFL) and, on average, 2.7 times higher than in the other experimental variants 
(Figure 3B). Moreover, there was an increase in both the fresh and dry weight of the root in RL (Figure 3B,E) and dry weight of needles in BL and RL in relation to WFL control (Figure 3D). In general, RL led to a more intensive development of the root system of the seedlings and an increase in the number of lateral roots of the first and second orders (Figure 2). Under the influence of RL, in the hypocotyls of the seedlings, 1.7 times more xylem cells were formed compared to the other variants of the experiment (Figure 3C), in the absence of any differences in the total area of the hypocotyls (Figure 3F). It is important to note that the growth of xylem under RL was not accompanied by thickening of the hypocotyls (Figure 3F), but the area of the xylem increased relative to other tissues (Figure 3G,H), while the diameter of xylem cells did not differ significantly (Figure 3I).
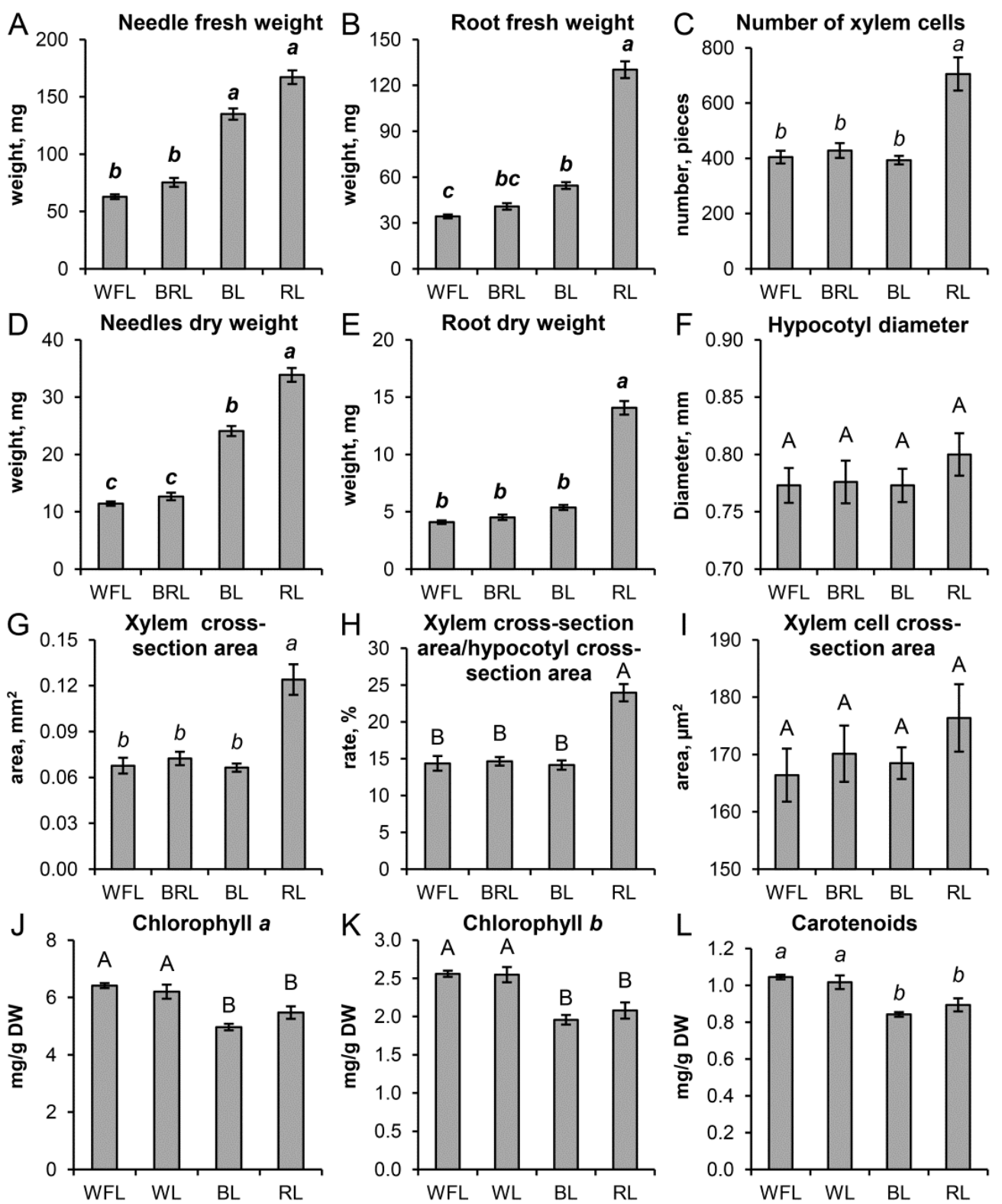

Figure 3. Effect of light quality on the needle (A) and root (B) fresh weight (mg); number of xylem cells (C) (pieces); needle (D) and root (E) dry weight (mg, DW); hypocotyl diameter (F) (mm); xylem cross-section area $(\mathbf{G})(\mathrm{mm})$; xylem cross-section area and hypocotyls cross-section area ratio $(\mathbf{H})(\%)$; xylem cell cross-section area (I) $\left(\mu \mathrm{m}^{2}\right)$; and content of Chl $a(\mathbf{J}) \mathrm{mg} / \mathrm{g} \mathrm{DW}, \mathrm{Chl} b(\mathbf{K}) \mathrm{mg} / \mathrm{g}$ DW, and total carotenoids $(\mathbf{L}) \mathrm{mg} / \mathrm{g} \mathrm{DW}$ in P. sylvestris seedlings. Values are the mean $\pm \mathrm{SE}$. Different capital 
letters denote statistically significant differences in the means at $p<0.05$ (ANOVA followed by Duncan's method). Different italic letters denote statistically significant differences in the means at $p<0.05$ (Kruskal-Wallis ANOVA of the ranks followed by the Student-Newman-Keuls post hoc test). Different boldface italic letters denote statistically significant differences in the means at $p<0.05$ (Kruskal-Wallis ANOVA of the ranks followed by the Dunn's method).

\subsection{Contents of Photosynthetic Pigments}

When grown on a narrowband RL and BL, a reduced content of chlorophylls and carotenoids was observed (by an average of $10-20 \%$ ), while the BRL and WFL variants were comparable (Figure 3J-L).

\subsection{Fluorescence Parameters and $\mathrm{CO}_{2}$ Gas Exchange}

The photosystem II (PSII) maximum quantum yield $\left(\mathrm{F}_{\mathrm{v}} / \mathrm{F}_{\mathrm{m}}\right)$ was approximately 0.81 and did not depend on the light quality used in the experiments (Table 2).

Table 2. Effect of light quality on the net photosynthetic and respiration rates, $R / P_{n}$ ratio, $\left(P_{n}-R\right)$ difference, PSII maximum quantum yield $\left(\mathrm{F}_{\mathrm{v}} / \mathrm{F}_{\mathrm{m}}\right)$, effective quantum yield $\mathrm{Y}(\mathrm{II})$, performance index PSII (PI $\left.\mathrm{ABS}\right)$, and nonphotochemical fluorescence quenching (NPQ) in 6-week-old P. sylvestris seedlings. Values are the mean \pm SE. Different normal-type letters denote statistically significant differences in the means at $p<0.05$ (ANOVA followed by Duncan's method).

\begin{tabular}{ccccc}
\hline Parameter & WFL & BRL & BL & RL \\
\hline $\mathrm{P}_{\mathrm{n}}, \mu \mathrm{mol} \mathrm{CO}_{2} \mathrm{~m}^{-2} \mathrm{~s}^{-1}$ & $14.4 \pm 2.1^{\mathrm{ab}}$ & $16.3 \pm 0.2^{\mathrm{a}}$ & $13.7 \pm 0.3^{\mathrm{b}}$ & $12.1 \pm 0.3^{\mathrm{c}}$ \\
$\mathrm{R}, \mu \mathrm{mol} \mathrm{CO} \mathrm{m}^{-2} \mathrm{~s}^{-1}$ & $8.7 \pm 0.8^{\mathrm{a}}$ & $8.8 \pm 0.1^{\mathrm{a}}$ & $5.1 \pm 0.2^{\mathrm{b}}$ & $2.1^{\mathrm{a}} \pm 0.1^{\mathrm{c}}$ \\
$\mathrm{R} / \mathrm{P}_{\mathrm{n}}$ & $0.62 \pm 0.12^{\mathrm{a}}$ & $0.54 \pm 0.06^{\mathrm{a}}$ & $0.37 \pm 0.02^{\mathrm{b}}$ & $0.17^{\mathrm{a}} \pm 0.01^{\mathrm{c}}$ \\
$\left(\mathrm{P}_{\mathrm{n}}-\mathrm{R}\right), \mu \mathrm{mol} \mathrm{CO}_{2} \mathrm{~m}^{-2} \mathrm{~s}^{-1}$ & $5.7 \pm 0.5^{\mathrm{d}}$ & $7.5 \pm 0.2^{\mathrm{c}}$ & $8.6 \pm 0.1^{\mathrm{b}}$ & $10.0 \pm 0.2^{\mathrm{a}}$ \\
$\mathrm{F}_{\mathrm{V}} / \mathrm{F}_{\mathrm{m}}$ & $0.814 \pm 0.005^{\mathrm{a}}$ & $0.803 \pm 0.001^{\mathrm{a}}$ & $0.815 \pm 0.007^{\mathrm{a}}$ & $0.812^{\mathrm{a}} \pm 0.006^{\mathrm{a}}$ \\
$\mathrm{PI}_{\mathrm{ABS}}$ & $7.73 \pm 0.39^{\mathrm{b}}$ & $7.85 \pm 0.64^{\mathrm{b}}$ & $6.45 \pm 0.82^{\mathrm{b}}$ & $10.21^{\mathrm{b}} \pm .59^{\mathrm{a}}$ \\
$\mathrm{Y}_{\mathrm{II}}$ & $0.52 \pm 0.01^{\mathrm{b}}$ & $0.44 \pm 0.03^{\mathrm{c}}$ & $0.50 \pm 0.01^{\mathrm{b}}$ & $0.57 \pm 0.01^{\mathrm{a}}$ \\
$\mathrm{NPQ}^{\mathrm{a}}$ & $0.86 \pm 0.10^{\mathrm{b}}$ & $1.67 \pm 0.21^{\mathrm{a}}$ & $0.95 \pm 0.12^{\mathrm{b}}$ & $0.66 \pm 0.17^{\mathrm{b}}$ \\
\hline
\end{tabular}

The PSII effective quantum yield (Y(II)) was the lowest in BRL plants (0.44); at the same time, in BL and WFL plants, this indicator remained at a comparable level and amounted to approximately 0.51 . The highest value of the Y(II) parameter was observed when growing seedlings under RL (0.57) (Table 2). The non-photochemical quenching (NPQ) parameter was the smallest in RL plants. When plants were grown on BL and WFL, NPQ was comparable and amounted to approximately 0.90 ; the highest NPQ value (1.67) was observed in the BRL plants (Table 2).

The intensity of $\mathrm{CO}_{2}$ gas exchange did not differ noticeably between the samples. The largest value of the parameter $\mathrm{P}_{\mathrm{n}}\left(16.3 \mu \mathrm{mol} \mathrm{CO} \mathrm{Cm}^{-2} \mathrm{~s}^{-1}\right)$ was observed in the BRL variant, and the smallest value was $12.1 \mu \mathrm{mol} \mathrm{CO} \mathrm{Cm}^{-2} \mathrm{~s}^{-1}$ in the RL variant, while the photosynthesis rate in the seedlings under the WFL and BL conditions was intermediate (Table 2).

The respiration rate $(\mathrm{R})$ in the WFL and BRL variants was the highest (approximately $8.8 \mu \mathrm{mol} \mathrm{CO} \mathrm{CO}^{-2} \mathrm{~s}^{-1}$ ), while in BL and RL plants, this value was reduced to 5.1 and $2.1 \mu \mathrm{mol} \mathrm{CO} \mathrm{CO}^{-2} \mathrm{~s}^{-1}$, respectively. As a consequence, the calculated parameters of the $R / P_{n}$ ratio and the $P_{n}-R$ carbon balance changed accordingly. The respiration/photosynthesis ratio was the highest in the WFL and BRL variants, lower in the BL variant, and the lowest in the RL plants (0.17). At the same time, the highest value of the carbon balance, assessed by the difference between the rates of photosynthesis and respiration, was observed in the RL variant (Table 2).

The PSII performance index $\left(\mathrm{PI}_{\mathrm{ABS}}\right)$ was on average 1.5 times higher in the RL variant than in the other variants. At the same time, all other options did not differ significantly among themselves (Table 2). 


\subsection{Gene Expression}

The transcript level of genes involved in hormonal signaling of cytokinins and auxins significantly changed in the variants of narrow-band light. Expression of the HPT1 gene in the needles of RL plants was increased almost two times, and in the roots, it was 2.7 times higher than that in the WFL control (Figure 4A,D).
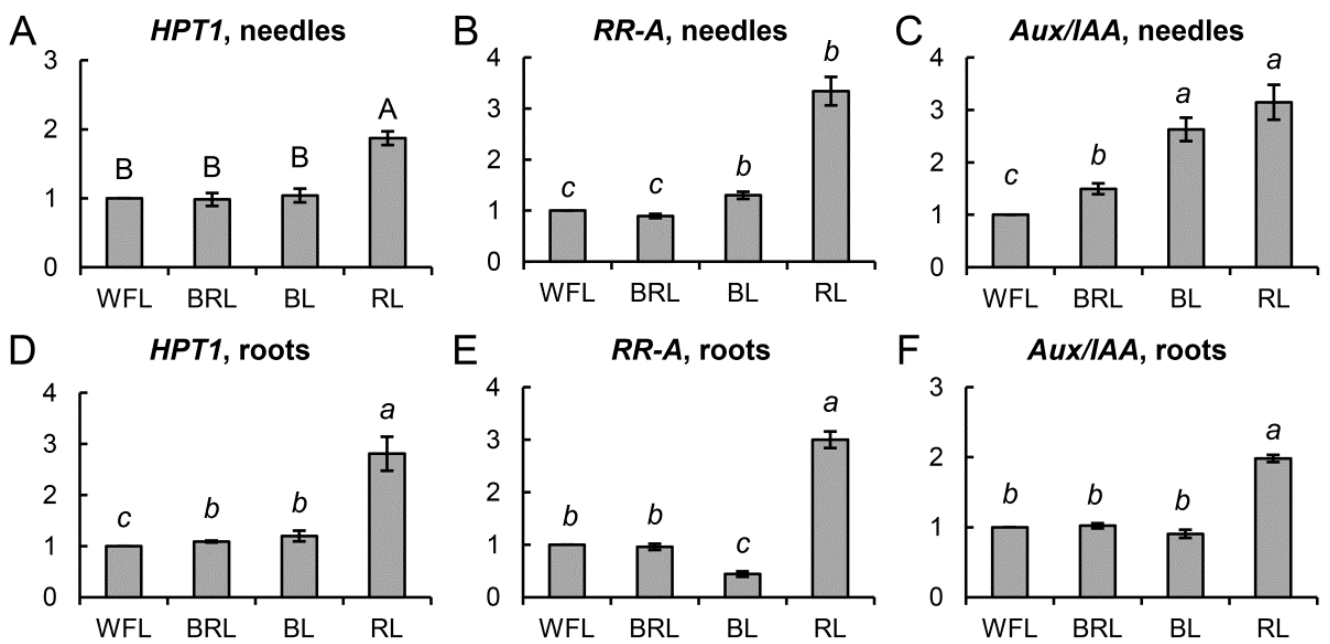

Figure 4. Effect of light quality on the transcript levels of different groups of genes in $P$. sylvestris seedlings. HPT1, RR-A, and $A u x / I A A$ in needles $(\mathbf{A}-\mathbf{C})$ and roots (D-F). The mRNA levels of the genes were expressed as the BRL, BL, RL/WFL ratio (fold change BRL, BL, RL/WFL). Values are the mean \pm SE. Different capital letters denote statistically significant differences in the means at $p<0.05$ (ANOVA followed by Duncan's method). Different italic letters denote statistically significant differences in the means at $p<0.05$ (Kruskal-Wallis ANOVA of the ranks followed by the Student-Newman-Keuls post hoc test).

At the same time, the level of $R R-A$ transcription in the RL variant was 3.3 and 3.0 times higher than that in WFL needles (Figure 4B) and roots (Figure 4E), respectively. In contrast, in the roots of the $\mathrm{BL}$ variant, $R R-A$ expression was more than 2 -fold lower than that in the WFL control (Figure 4E). In the needles of the seedlings, the expression of the Aux/IAA gene in the RL and BL plants was, on average, 2.8 times higher than that in the WFL control (Figure $4 \mathrm{C}$ ). At the same time, in the roots, the level of $A u x / I A A$ transcripts was higher only in the RL variant (Figure $4 \mathrm{~F}$ ).

We also studied the transcription of genes responsible for light signaling and the synthesis of secondary metabolites, such as the transcription factors PIF3, CHS, and STS. The expression level of the PIF3 gene in the RL variant compared to that of WFL was reduced in needles by $30 \%$ (Figure $5 \mathrm{~A}$ ), while that of the CHS gene, on the contrary, increased 1.5 times compared to those of BRL and WFL (Figure 5B).

An increase in the transcript level of the STS gene was also observed more than 11 times in needles (Figure 5C) and more than 23 times in roots (Figure 5F) in the RL variant, and approximately 4 times in needles and 6 times in roots in the BL variant (Figure 5C,F).

Over the course of the experiment, the gene expression of the main proteins of photosystems I and II was studied. Among the large number of analyzed genes ( $p s b A, B, C, D, S$; pet $A, C, D, E ; p s a A, B ; f l v A, B ; L h c 1,2)$, only the transcription levels of $p s b A$ encoding the PSII key protein D1 changed significantly and reliably. Thus, in variants BRL and BL, a twofold increase in the level of $p s b A$ transcripts was observed, while RL did not cause changes in the expression of this gene (Figure 6A). 

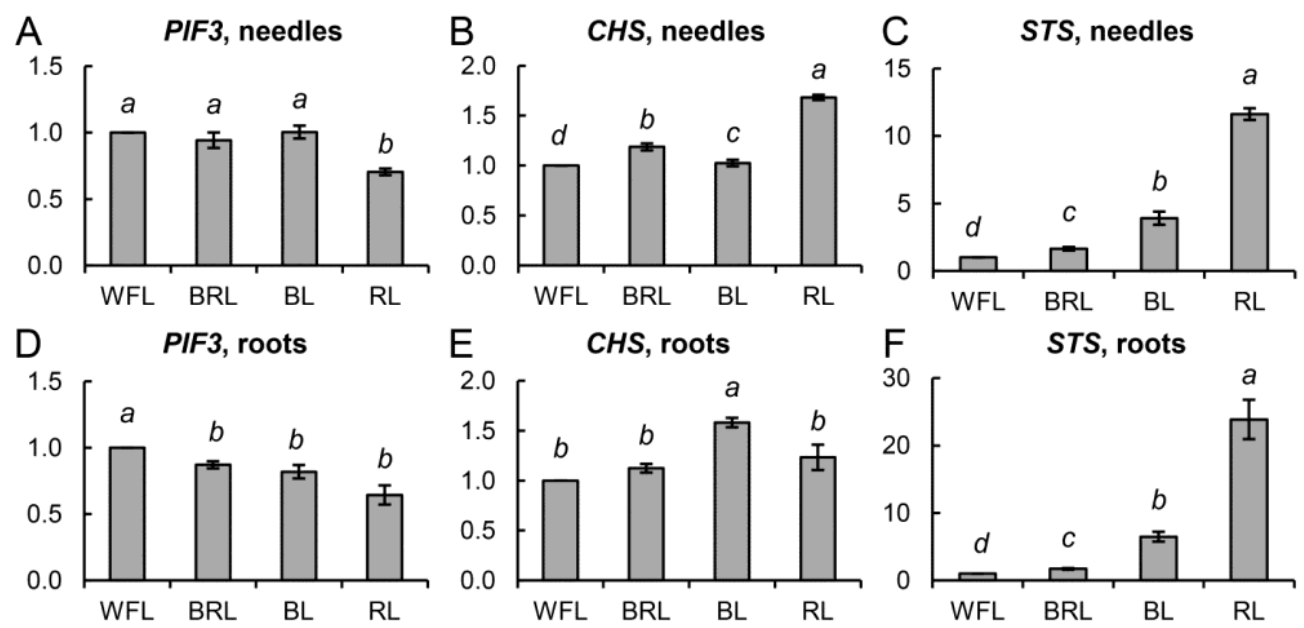

Figure 5. Effect of light quality on the transcript levels of different groups of genes in P. sylvestris seedlings. PIF3, CHS, and STS in needles (A-C), and roots (D-E). The mRNA levels of the genes were expressed as the BRL, BL, RL/WFL ratio (fold change BRL, BL, RL/WFL). Different italic letters denote statistically significant differences in the means at $p<0.05$ (Kruskal-Wallis ANOVA of the ranks followed by the Student-Newman-Keuls post hoc test).
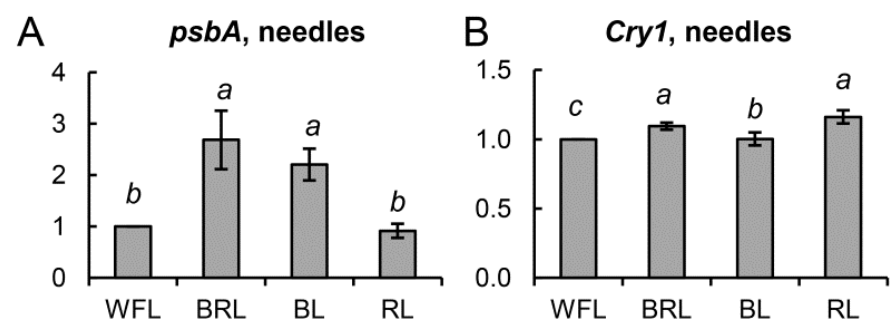

C Cry2, needles
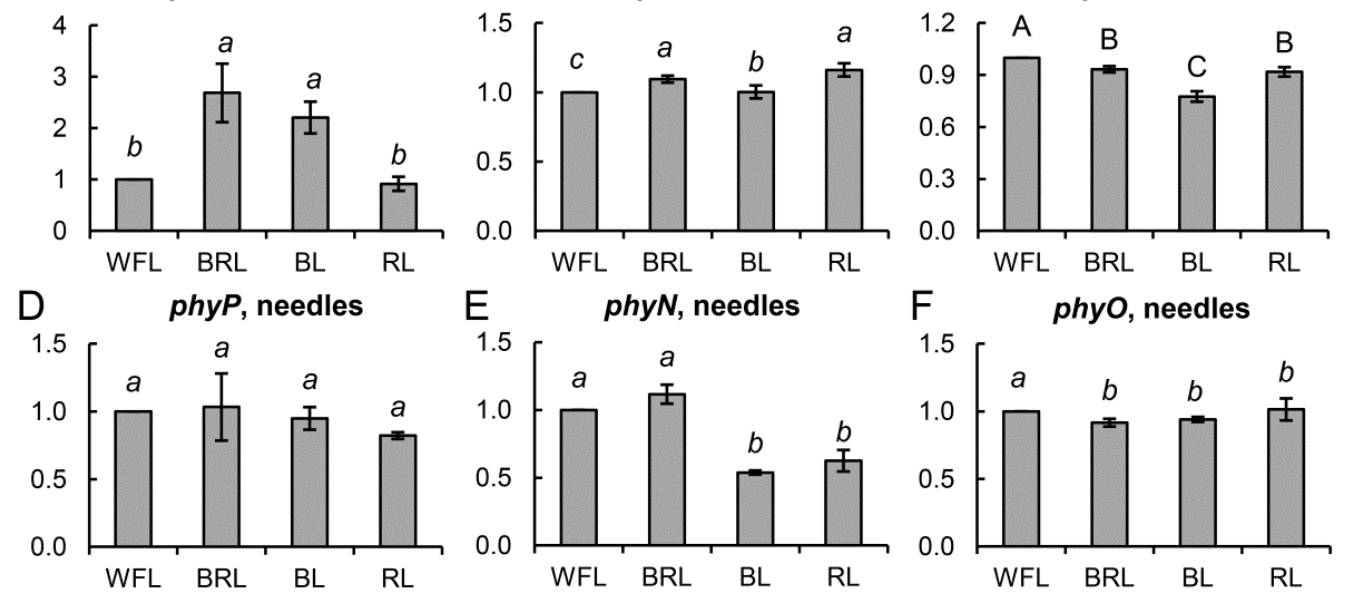

Figure 6. Effect of light quality on the transcript levels of different groups of genes in $P$. sylvestris needles. psbA (A), Cry1 (B), and Cry2 (C); and phyP (D), phyN (E), and phyO (F). The mRNA levels of the genes were expressed as the BRL, BL, RL/WFL ratio (fold change BRL, BL, RL/WFL). Values are the mean \pm SE. Different capital letters denote statistically significant differences in the means at $p<0.05$ (ANOVA followed by Duncan's method). Different italic letters denote statistically significant differences in the means at $p<0.05$ (Kruskal-Wallis ANOVA of the ranks followed by the Student-Newman-Keuls post hoc test).

In addition, the gene expression of apoproteins of the main blue and red light photoreceptors was studied (Figure 6B-D,F). Significant differences were observed in the phyN gene transcripts, the level of which was reduced by almost 2-fold in BL and RL relative to the WFL control (Figure 6E). Significant but negligible differences were observed in the transcript levels of Cry1 and Cry2 genes (Figure 6B,C).

\section{Discussion}

Seedlings of P. sylvestris are photophilous; however, in the first few seasons of their life, they can only be higher than the surrounding herbaceous plants for a short period of time, which causes a lack of light, primarily in the red and blue spectral ranges. It is known 
that RL, in contrast to BL, has a significant effect on the stem growth, stem diameter, and size and dry weight of Picea abies needles [20]. Thus, in contrast to growing under BL and WFL, RL increased the biomass and stem diameter of Brassica oleracea plants [28]. At the same time, photosynthesis in RL plants was noticeably higher than in other variants, which probably led to an increasing biomass [28]. In our work, RL influenced the morphology of P. sylvestris seedlings, which was manifested in an increase in the mass of the root system by more than 3.8 times, complications of root branching, and an increase in the mass of the needles by 2.6 times in comparison with WFL. At the same time, RL caused a slight decrease in $\mathrm{CO}_{2}$ gas exchange, as well as a significant (more than four times) decrease in respiration intensity relative to those of the WFL control (Table 2). This indicates a greater assimilation of carbon in RL plants. The slight difference in the pigment content is consistent with the fact that their photosynthetic apparatus is not dependent on light.

Regarding photochemical processes, the effective PSII quantum yield Y(II) was the highest in RL plants but the value of NPQ was small. We suppose that the increased Y(II) and complementary decreased NPQ are due to preferential excitation of photosystem I (PSI) by RL with a wavelength $>685 \mathrm{~nm}$. The contribution of the long-wave light is quite significant in red LEDs spectrum (Figure 1). Such light can lead to faster re-oxidization of the plastoquinone pool and reopening of PSII reaction centers [29]. As a result, reaction centers use absorbed light more efficiently.

Gymnosperms have the ability to synthesize chlorophyll in the dark due to the presence of the three genes of light-independent protochlorophyllide oxidoreductase $L, N$, and $\mathrm{B}(\mathrm{ChlL}, \mathrm{ChlN}$, and $\mathrm{ChlB})$ involved in the light-independent reduction of protochlorophyllide to chlorophyllide [30]. This also confirms the presence of special light regulation in conifers, which makes them a unique object of research.

The features of development and metabolism in plants induced by light of different spectral composition are primarily mediated by changes in the expression of lightdependent genes [20,30], including those encoding chloroplast proteins, photoreceptor apoproteins, transcription factors, and enzymes involved in the biosynthesis of secondary metabolites [31] and phytohormone signaling. In our work, we showed that several genes involved in the response to RL or BL are expressed in different ways. For example, the level of transcription of the $p s b A$ gene of the PSII main protein D1 increased in BL and BRL plants but decreased in RL plants (Figure 6A). This response to RL, as well as the accumulation of $p s b A$ transcripts under BL and RL conditions, is a typical response for most flowering plants [32]. Unfortunately, we did not observe noticeable changes in the expression of photoreceptor genes, with the exception of phyN (Figure 6B-F); on the other hand, under conditions of prolonged exposure to light of different spectra, it is impossible to exclude the presence of a sufficient number of active forms of photoreceptors, as well as the presence of regulation at the level of light signaling. In another work, it was shown that phyN is able to respond to different ratios of BL and RL in Scots pine seedlings of different growing regions [6].

The quality of light influences photomorphogenesis, photosynthesis, and plant growth through appropriate photoreceptors $[33,34]$. However, no significant difference in the expression level of photoreceptor genes was found between the light variants BL and RL, which is consistent with previous studies performed on A. thaliana seedlings [35]. The gene expression profiles of $A$. thaliana plants grown under BRL, RL, and BL were similar in all variants, and a significant proportion of differentially expressed genes under BL were also induced under RL. This indicates that the expression of light-regulated genes in $P$. sylvestris is not a unique response to BL or RL and that light of different spectral composition is able to regulate metabolic patterns in a similar way through the regulation of light signaling genes.

Transcription factors play an important role in the regulation of photosynthetic apparatus sensitivity to light of different spectral composition, since they, together with photoreceptors, are involved in the transduction of both light and hormonal signals. Phytochrome signaling transcription factors (PIFs) are important negative regulatory proteins 
that can alter the expression of a number of associated genes [6,36]. We observed a $30 \%$ decrease in the expression of the PIF3 gene in RL plants, which may be associated with the activation of light signaling at the level of transcription of the corresponding genes (Figure 5A,D). These results demonstrate that the mechanisms by which light of different spectral composition controls the growth of $P$. sylvestris may involve angiosperm light signaling pathways. Transcription factors, together with photoreceptors, can influence the expression of hormonal signaling genes. Thus, a direct link between cytokinin signaling and light was found in a study demonstrating the key role of A-type RR regulators of cytokinin signaling [37-39]. RL induces $R R-A$ expression in a PHYB-dependent manner. Thus, the overexpressing $R R-A$ leads to hypersensitivity to RL [37]. Later research showed an important role for RR-A in photomorphogenesis [40,41]. RR-As are able to interact with PHYB via the cytokinin receptor (AHK). In support of this, we observed an increased expression of one of the main proteins of cytokinin signaling transduction (HPT1) by more than two times in roots and needles in the RL variant (Figure 4A,D). In addition, the PIFs are also involved in phytochrome-mediated regulation of auxin signaling under RL conditions, since these TFs are able to bind to the promoter regions of the $A u x / I A A$ genes. PIFs modulate plant growth by directly controlling the expression of auxin signaling genes [11]. We assume that this, to a certain extent, explains the greater number of xylem cells in hypocotyls in the RL variant and, as a consequence, a greater accumulation of plant biomass (Figure 4C,F).

Along with the growth and development of plants, changes in the spectral composition of light also affect secondary metabolism. Chalcone synthase, the first enzyme in the biosynthesis of flavonoids, is expressed in needles of RL plants and in roots of BL plants (Figure 5B,E). In our study, RL stimulated gene families associated with the biosynthesis of the flavonoids (CHS, STS). Stilbenes are a family of polyphenolic secondary metabolites that act as phytoalexins [42,43]. Previously, it was shown that treatment with RL suspension culture of grape cells increased the biosynthesis of stilbenes [44,45]. In our study, we observed an increase in STS expression in roots and needles by more than 3.5 times in BL plants and more than 10 times in RL plants (Figure 5C,F). It can be assumed that, as in grape plants, stilbenes are involved in the photoadaptation of $P$. sylvestris plants to narrow-band RL and BL.

\section{Conclusions}

In this work, we tried to answer the question of what spectral range of light can be most favorable for the growth of $P$. sylvestris seedlings. It was shown that the RL spectral range is most favorable for growing $P$. sylvestris seedlings in a hydroculture, which manifested itself in both a greater mass of aboveground and underground organs and in an increase in the number of xylem cells. We found an increase in the level of transcripts of genes for auxin and cytokinin signaling (HPT1, RR-A, and $A u x / I A A)$ and a decrease in the expression of TF PIF3, which in turn could activate the expression of a number of genes associated with the synthesis of secondary metabolites (CHS, STS). Based on the data obtained, we assumed that the large biomass of $P$. sylvestris plants under the RL might be due to a large accumulation of carbon in the needles, which corresponds to a better balance between photosynthesis and respiration, as well as to the increased activity of cytokinins and auxins in seedlings. Although P. sylvestris seedlings are able to grow in conditions of low RL content at the beginning of ontogenesis, better RL radiation can significantly improve their growth and development. The obtained results can serve as a basis for the development of a technology for the accelerated cultivation of planting material during reforestation when growing seedlings under artificial lighting, and they can also be used in biotechnology.

Author Contributions: Investigation, formal analysis, data curation, and responsible for the experimental part of the manuscript: P.P., V.D.K., Y.I., A.I., and A.K.; obtained main results: P.P., Y.I., A.I., A.S., V.S.; designed the experiments, interpreted the main results, drew the main conclusions, and 
prepared the first version of the manuscript: V.D.K., P.P., S.I.A. and V.V.K. All authors have read and agreed to the published version of the manuscript.

Funding: The research was carried out within the state assignment of Ministry of Science and Higher Education of the Russian Federation (theme No. 121040800153-1).

Institutional Review Board Statement: Not applicable.

Informed Consent Statement: Not applicable.

Data Availability Statement: The data presented in this study are available on request from the corresponding authors. The data are not public.

Conflicts of Interest: The authors declare no conflict of interest.

\section{References}

1. Casal, J.J. Shade avoidance. Arab. Book 2012, 10, e0157. [CrossRef]

2. Taulavuori, K.; Sarala, M.; Karhu, J.; Taulavuori, E.; Kubin, E.; Laine, K.; Poikolainen, J.; Pesonen, E. Elongation of Scots pine seedlings under blue light depletion. Silva Fenn. 2005, 39, 131-136. [CrossRef]

3. Hernández, R.; Kubota, C. Physiological responses of cucumber seedlings under different blue and red photon flux ratios using LEDs. Environ. Exp. Bot. 2016, 121, 66-74. [CrossRef]

4. Franklin, K.A. Photomorphogenesis: Plants feel blue in the shade. Curr. Biol. 2016, 26, R1275-R1276. [CrossRef] [PubMed]

5. Dyderski, M.K.; Paź, S.; Frelich, L.E.; Jagodziński, A.M. How much does climate change threaten European forest tree species distributions? Glob. Chang. Biol. 2018, 24, 1150-1163. [CrossRef]

6. Alakärppä, E.; Taulavuori, E.; Valledor, L.; Marttila, T.; Jokipii-Lukkari, S.; Karppinen, K.; Nguyen, N.; Taulavuori, K.; Häggman, H. Early growth of Scots pine seedlings is affected by seed origin and light quality. J. Plant Physiol. 2019, 237, 120-128. [CrossRef] [PubMed]

7. Ahmad, M. Photocycle and signaling mechanisms of plant cryptochromes. Curr. Opin. Plant Biol. 2016, 33, 108-115. [CrossRef]

8. Mathews, S. Evolutionary studies illuminate the structural-functional model of plant phytochromes. Plant Cell. 2010, 22, 4-16. [CrossRef] [PubMed]

9. Clapham, D.H.; Kolukisaoglu, H.Ü.; Larsson, C.T.; Qamaruddin, M.; Ekberg, I.; Wiegmann-Eirund, C.; Schneider-Poetsch, H.A.W.; von Arnold, S. Phytochrome types in Picea and Pinus. Expression patterns of PHYA-related types. Plant Mol. Biol. 1999, 40, 669-678. [CrossRef] [PubMed]

10. Clapham, D.H.; Ekberg, I.; Eriksson, G.; Norell, L.; Vince-Prue, D. Requirement for far-red light to maintain secondary needle extension growth in northern but not southern populations of Pinus sylvestris (Scots pine). Physiol. Plantarum. 2002, 114, 207-212. [CrossRef] [PubMed]

11. Zdarska, M.; Dobisová, T.; Gelová, Z.; Pernisová, M.; Dabravolski, S.; Hejátko, J. Illuminating light, cytokinin, and ethylene signalling crosstalk in plant development. J. Exp. Bot. 2015, 66, 4913-4931. [CrossRef] [PubMed]

12. Hornitschek, P.; Kohnen, M.V.; Lorrain, S.; Rougemont, J.; Ljung, K.; López-Vidriero, I.; Franco-Zorrilla, J.M.; Solano, R.; Trevisan, M.; Pradervand, S.; et al. Phytochrome interacting factors 4 and 5 control seedling growth in changing light conditions by directly controlling auxin signaling. Plant J. 2012, 71, 699-711. [CrossRef] [PubMed]

13. Lau, O.S.; Deng, X.W. Plant hormone signaling lightens up: Integrators of light and hormones. Curr. Opin. Plant Biol. 2010, 13, 571-577. [CrossRef] [PubMed]

14. Kurepin, L.V.; Emery, R.N.; Pharis, R.P.; Reid, D.M. The interaction of light quality and irradiance with gibberellins, cytokinins and auxin in regulating growth of Helianthus annuus hypocotyls. Plant Cell Environ. 2007, 30, 147-155. [CrossRef] [PubMed]

15. Pierik, R.; Keuskamp, D.H.; Sasidharan, R.; Djakovic-Petrovic, T.; de Wit, M.; Voesenek, L.A. Light quality controls shoot elongation through regulation of multiple hormones. Plant Signal. Behav. 2009, 4, 755-756. [CrossRef] [PubMed]

16. Kurepin, L.V.; Walton, L.J.; Hayward, A.; Emery, R.N.; Pharis, R.P.; Reid, D.M. Interactions between plant hormones and light quality signaling in regulating the shoot growth of Arabidopsis thaliana seedlings. Botany 2012, 90, 237-246. [CrossRef]

17. Gubler, F.; Hughes, T.; Waterhouse, P.; Jacobsen, J. Regulation of dormancy in barley by blue light and after-ripening: Effects on abscisic acid and gibberellin metabolism. Plant Physiol. 2008, 147, 886-896. [CrossRef]

18. Reddy, S.K.; Finlayson, S.A. Phytochrome B promotes branching in Arabidopsis by suppressing auxin signaling. Plant Physiol. 2014, 164, 1542-1550. [CrossRef]

19. Zhang, Z.; Ji, R.; Li, H.; Zhao, T.; Liu, J.; Lin, C.; Liu, B. CONSTANS-LIKE 7 (COL7) is involved in Phytochrome B (phyB)-mediated light-quality regulation of auxin homeostasis. Mol. Plant 2014, 7, 1429-1440. [CrossRef]

20. OuYang, F.; Mao, J.F.; Wang, J.; Zhang, S.; Li, Y. Transcriptome analysis reveals that red and blue light regulate growth and phytohormone metabolism in Norway spruce [Picea abies (L.) Karst.]. PLoS ONE 2015, 10, e0127896. [CrossRef] [PubMed]

21. Ivanov, Y.V.; Kartashov, A.V.; Ivanova, A.I.; Savochkin, Y.V.; Kuznetsov, V.V. Effects of zinc on Scots pine (Pinus sylvestris L.) seedlings grown in hydroculture. Plant Physiol. Bioch. 2016, 102, 1-9. [CrossRef]

22. Lichtenthaler, H.K. [34] Chlorophylls and carotenoids: Pigments of photosynthetic biomembranes. In Methods in Enzymology; Packer, L., Douce, R., Eds.; Academic Press: Cambridge, MA, USA, 1987; Volume 148, pp. 350-382. [CrossRef] 
23. Lankin, A.V.; Kreslavski, V.D.; Khudyakova, A.Y.; Zharmukhamedov, S.K.; Allakhverdiev, S.I. Effect of naphthalene on photosystem 2 photochemical activity of pea plants. Biochemistry 2014, 79, 1216-1225. [CrossRef]

24. Goltsev, V.N.; Kalaji, H.M.; Paunov, M.; Baba, W.; Horaczek, T.; Mojski, J.; Kociel, H.; Allakhverdiev, S.I. Variable chlorophyll fluorescence and its use for assessing physiological condition of plant photosynthetic apparatus. Russ. J. Plant Physiol. 2016, 63, 869-893. [CrossRef]

25. Kolosova, N.; Miller, B.; Ralph, S.; Ellis, B.E.; Douglas, C.; Ritland, K.; Bohlmann, J. Isolation of high-quality RNA from gymnosperm and angiosperm trees. Biotechniques 2004, 36, 821-824. [CrossRef]

26. Pashkovskiy, P.P.; Vankova, R.; Zlobin, I.E.; Dobrev, P.; Ivanov, Y.V.; Kartashov, A.V.; Kuznetsov, V.V. Comparative analysis of abscisic acid levels and expression of abscisic acid-related genes in Scots pine and Norway spruce seedlings under water deficit. Plant Physiol. Bioch. 2019, 140, 105-112. [CrossRef] [PubMed]

27. Mitra, P.P.; Loqué, D. Histochemical staining of Arabidopsis thaliana secondary cell wall elements. J. Vis. Exp. 2014, 87, 51381. [CrossRef]

28. Chen, X.W.; Liu, S.Q.; Wang, Y.; Liu, J.K.; Feng, L. Effects of different LED light qualities on growth, photosynthetic characteristics and nutritional quality of savoy. Ying Yong Sheng Tai Xue Bao 2014, 25, 1955-1962.

29. Zhen, S.; van Iersel, M.W. Far-red light is needed for efficient photochemistry and photosynthesis. J. Plant Physiol. 2017, 209, 115-122. [CrossRef] [PubMed]

30. Ranade, S.S.; Delhomme, N.; García-Gil, M.R. Global gene expression analysis in etiolated and de-etiolated seedlings in conifers PLoS ONE 2019, 14, e0219272. [CrossRef] [PubMed]

31. Gyula, P.; Schäfer, E.; Nagy, F. Light perception and signalling in higher plants. Curr. Opin. Plant Biol. 2003, 6, 446-452. [CrossRef]

32. Zheng, J.; Hu, M.J.; Guo, Y.P. Regulation of photosynthesis by light quality and its mechanism in plants. Ying Yong Sheng Tai Xue Bao 2008, 19, 1619-1624. [PubMed]

33. Kreslavski, V.D.; Strokina, V.V.; Pashkovskiy, P.P.; Balakhnina, T.I.; Voloshin, R.A.; Alwasel, S.; Kosobryukhov, A.A.; Allakhverdiev, S.I. Deficiencies in phytochromes A and B and cryptochrome 1 affect the resistance of the photosynthetic apparatus to high-intensity light in Solanum lycopersicum. J. Photoch. Photobio. B 2020, 210, 111976. [CrossRef]

34. Kreslavski, V.D.; Strokina, V.V.; Khudyakova, A.Y.; Shirshikova, G.N.; Kosobryukhov, A.A.; Pashkovskiy, P.P.; Alwasel, S.; Allakhverdiev, S.I. Effect of high-intensity light and UV-B on photosynthetic activity and the expression of certain light-responsive genes in $A$. thaliana phy $A$ and phyB mutants. BBA-Bioenergetics 2021, 1862, 148445. [CrossRef] [PubMed]

35. Ma, L.; Li, J.; Qu, L.; Hager, J.; Chen, Z.; Zhao, H.; Deng, X.W. Light control of Arabidopsis development entails coordinated regulation of genome expression and cellular pathways. Plant Cell 2001, 13, 2589-2607. [CrossRef] [PubMed]

36. Rohde, A.; Ruttink, T.; Hostyn, V.; Sterck, L.; Van Driessche, K.; Boerjan, W. Gene expression during the induction, maintenance, and release of dormancy in apical buds of poplar. J. Exp. Bot. 2007, 58, 4047-4060. [CrossRef] [PubMed]

37. Sweere, U.; Eichenberg, K.; Lohrmann, J.; Mira-Rodado, V.; Bäurle, I.; Kudla, J.; Nagy, F.; Schäfer, E.; Harter, K. Interaction of the response regulator ARR4 with phytochrome B in modulating red light signaling. Science 2001, 294, 1108-1111. [CrossRef]

38. Fankhauser, C. Light perception in plants: Cytokinins and red light join forces to keep phytochrome B active. Trends Plant Sci. 2002, 7, 143-145. [CrossRef]

39. Al-Sady, B.; Ni, W.; Kircher, S.; Schäfer, E.; Quail, P.H. Photoactivated phytochrome induces rapid PIF3 phosphorylation prior to proteasome-mediated degradation. Mol. Cell 2006, 23, 439-446. [CrossRef]

40. Thomas, T.H.; Hare, P.D.; van Staden, J. Phytochrome and cytokinin responses. Plant Growth Regul. 1997, 23, 105-122. [CrossRef]

41. Mira-Rodado, V.; Sweere, U.; Grefen, C.; Kunkel, T.; Fejes, E.; Nagy, F.; Schäfer, E.; Harter, K. Functional cross-talk between two-component and phytochrome B signal transduction in Arabidopsis. J. Exp. Bot. 2007, 58, 2595-2607. [CrossRef] [PubMed]

42. Dubrovina, A.S.; Kiselev, K.V. Regulation of stilbene biosynthesis in plants. Planta 2017, 246, 597-623. [CrossRef]

43. Valletta, A.; Iozia, L.M.; Leonelli, F. Impact of environmental factors on stilbene biosynthesis. Plants 2021, 10, 90. [CrossRef] [PubMed]

44. Tassoni, A.; Durante, L.; Ferri, M. Combined elicitation of methyl-jasmonate and red light on stilbene and anthocyanin biosynthesis. J. Plant Physiol. 2012, 169, 775-781. [CrossRef] [PubMed]

45. Ahn, S.Y.; Kim, S.A.; Choi, S.J.; Yun, H.K. Comparison of accumulation of stilbene compounds and stilbene related gene expression in two grape berries irradiated with different light sources. Hortic. Environ. Biotechnol. 2015, 56, 36-43. [CrossRef] 